\title{
Production of the biotechnologically relevant AFP from Aspergillus giganteus in the yeast Pichia pastoris.
}

Belén López-García ${ }^{a}$, Ana Beatriz Moreno ${ }^{a}$, Blanca San Segundo ${ }^{a}$, Vivian De los Ríos ${ }^{b}$, James M. Manning ${ }^{c}$, José G. Gavilanes ${ }^{d}$ and Álvaro Martínez-del$\mathrm{Pozo}^{\mathrm{d}, *}$

${ }^{a}$ Centre de Recerca en Agrigenómica (CRAG) CSIC-IRTA-UAB, Departamento de Genética Molecular, Instituto de Biología Molecular de Barcelona, CSIC, Jordi Girona 18, 08034 Barcelona, Spain.

${ }^{\text {b}}$ Centro de Investigaciones Biológicas, C.S.I.C., Ramiro de Maeztu 9, 28040 Madrid, Spain.

${ }^{c}$ Biology, Northeastern University, 134 Mugar Life Sciences, 360 Huntington Avenue, Boston, MA 02115, U.S.A.

'Departamento de Bioquímica, Facultad de Química, Universidad Complutense, 28040 Madrid, Spain.

*Corresponding author: Tel: 3491394 4259; Fax: 34913944159.

E-mail address: alvaro@bbm1.ucm.es (A. Martínez-del-Pozo) 


\section{ABSTRACT}

The mould Aspergillus giganteus produces a basic, low molecular weight protein (AFP) showing in vitro and in vivo antifungal properties against important plant pathogens. AFP is secreted as an inactive precursor containing an amino-terminal extension of six amino acids (If-AFP) which is later removed to produce the active protein. The molecular basis to explain this behavior and the features that determine the fungal specificity of this protein are not completely solved. In this work, the mature AFP (AFP*) and a version of AFP with an extended amino-terminal (proAFP) have been cloned and produced in the yeast Pichia pastoris. The two proteins have been purified to homogeneity and characterized from structural and functional points of view. AFP* produced is practically indistinguishable from the natural fungal protein in terms of its spectroscopic and antifungal properties while proAFP is mostly inactive under identical assay conditions. The availability of an active AFP protein produced in $P$. pastoris will allow getting further insights into the mode of action and targeting specificity of AFP by using site-directed mutagenesis approaches

Keywords: antifungal, antimicrobial, cysteine-rich, peptide.

Abbreviations used: $\mathrm{BMMH}$, buffered minimal methanol medium supplemented with histidine; AFP, antifungal protein from Aspergillus giganteus; AMPs, antimicrobial peptides; PDB, potato dextrose broth. 


\section{Introduction}

Peptides and small proteins exhibiting direct antimicrobial activity have been characterized from many organisms throughout all kingdoms [1]. The general biological role of antimicrobial peptides and proteins in defense against challenging microbes is recognized and they are proposed as promising tools for the development of new antifungal therapies in medicine and agriculture [24]. Moreover, the transgenic expression of antimicrobial genes has been successfully used to improve resistance to fungal diseases in many plant species [5-8].

Filamentous fungi themselves can be considered as valuable sources for the production of antifungal peptides and proteins $[9,10]$. One of these promising polypeptides is the antifungal protein (AFP) secreted by the mould Aspergillus giganteus. AFP is a basic, low molecular weight (51 residues long) protein showing in vitro antifungal properties against important plant pathogens, including Magnaporthe oryzae, Fusarium verticilloides, Phytophthora infestans, and Botrytis cinerea [11-15]. These fungi are responsible for important diseases in a large number of plants with agricultural and economical importance, such as rice, wheat, potato, or tomato. In addition, transgenic expression of the afp gene, either alone or in combination with other antimicrobial genes, has been shown to confer disease resistance [6,16-18].

AFP has been thoroughly characterized from structural and spectroscopic points of view, including the resolution of its three-dimensional structure in solution $[11,19]$. It displays the characteristic features of an oligonucleotide/oligosaccharide binding (OB-fold) structural motif [20] being a small and compact $\beta$-barrel composed of five highly twisted antiparallel $\beta$ strands. It should be also mentioned that cysteine pairing isomerism exists within its four disulfide bridges [19]. AFP is secreted as an inactive precursor (IfAFP) containing an amino-terminal extension of six amino acids [12].

AFP is also a member of an emerging family of small cysteine-rich antifungal proteins, secreted by ascomycetes [9]. Other well characterized member of the same family is PAF from Penicillium chrysogenum [9]. The structure of PAF is coincident in many aspects with that of AFP, including the impossibility of unambiguously assigning of the disulfide pattern [21]. Although PAF is closely related to AFP from a structural point of view, it shows slightly different functionality and antifungal specificity [9]. The paf gene has been recently cloned and the PAF polypeptide successfully produced in $P$. pastoris. This has allowed the determination of its three-dimensional structure in solution and the production and characterization of several interesting mutants [21].

Although an enormous number of peptides and proteins endowed with antimicrobial activity are now known, the mechanism by which most of them exert their activity has been only partially solved and still remains a matter of discussion [reviewed in 22]. Concerning AFP, it has been reported that this protein enters the fungal cells by its ability to interact with phospholipid membranes [11] thus causing membrane permeabilization in the target fungal cell $[15,23]$. In other studies, it was reported that AFP binds fungal cell wall chitin [24]. Apparently, the AFP protein enters into the fungal cell and targets the nucleus, as revealed by co-localization experiments of Alexa-labeled AFP with the SYTOX Green dye [15]. AFP would bind fungal nucleic acids promoting charge neutralization and condensation of DNA [15,20], maybe triggering 
apoptosis [23]. The available data suggest that it is this combination of fungal cell permeabilization, cell-penetrating ability and nucleic acid-binding activity of AFP that determines its potent antifungal activity. Unfortunately, the molecular basis for this behavior and, more important, the features that determine the fungal specificity of the protein are still far from solved. As stated above, the fact that PAF displays different specificity and presumably different cytotoxic mechanism [9] does not help us to reach a consensus on the mode of action of this family of antifungal proteins.

In order to further explore the molecular details by which AFP exerts its antifungal activity, both the mature protein and a version with an extended amino-terminal have been cloned and produced in the yeast $P$. pastoris. Both proteins have been purified to homogeneity and characterized from structural and functional points of view.

\section{Materials and Methods}

\section{Cloning procedures}

The Aspergillus cDNA sequence encoding the mature AFP protein (51 amino acids and the stop codon) was amplified by PCR using the pBSK(-)afp plasmid as template [17]. Two different afp plasmid constructs in which the mature AFP protein was translationally fused to the yeast $\alpha$-factor signal sequence for secretion were prepared. The first construct contained the afp cDNA fused to the complete yeast $\alpha$-factor signal peptide sequence (plasmid pPICZaproAFP). To obtain this plasmid, the afp cDNA was PCR amplified using the following primers: 5'GAATTCGCCACATACAATGGCAAA3' (N-terminal-A primer) and 5'TCTAGACTAGCAGTAGCACTTCCCC3' (C-terminal primer). During the PCR reaction, EcoRI and Xbal sites were introduced into the PCR amplified DNA fragment (underlined nucleotides in PCR primer sequences). Next, the afp cDNA sequence was inserted into the EcoRI and Xbal digested pPICZaA plasmid for expression in $P$. pastoris. In this way, the AFP cDNA was inserted in frame with the complete yeast $\alpha$-factor signal sequence, including the Kex2 and Ste13 signal cleavage sites (Fig. 1).

A second construct was prepared in which the mature AFP was fused to a mutated version of the yeast $\alpha$-factor sequence in which a deletion was introduced to remove the Ste13 cleavage sites (plasmid pPICZaAFP). For this, the oligonucleotide 5'GGGGTATCTCTCGAGAAAAGAGCCACATACAATGGCAAA3' (N-terminal-B primer) and the $\mathrm{C}$-terminal primers were used. A Xhol restriction site was introduced at the $\mathrm{N}$-terminal-B oligonucleotide primer suitable for the subsequent cloning steps (underlined nucleotides). Constructs, pPICZaproAFP (containing the full $\alpha$-factor signal peptide sequence) and pPICZ $\alpha A F P$ (the plasmid where the Ste13 signal cleavage sites had been removed) were verified by nucleotide sequencing (DNA sequence facility from the Universidad Complutense).

Protein production and purification. 
In order to produce the recombinant version of AFP in $P$. pastoris, plasmids $(1 \mu \mathrm{g})$ pPICZaproAFP and pPICZaAFP were digested with Sac I and used to transform KM71 cells by electroporation on a Bio-Rad Gene-Pulser apparatus as described [25]. The pPICZaA plasmid contains the gene that confers resistance to the antibiotic zeocin. Thus, after the pulse cells were immediately diluted with $1 \mathrm{ml}$ of cold $1 \mathrm{M}$ sorbitol and plated on YPD (1\% yeast extract, $2 \%$ peptone and $2 \%$ dextrose) medium containing $1 \mathrm{M}$ sorbitol and different amounts of zeocin (100-1500 $\mu \mathrm{g} / \mathrm{ml})$. Incubation at 30ㅇ $\mathrm{C}$ was performed until colonies appeared (4 days). In each case, the best producing colony was selected, among 10 tested, by small scale production experiments and SDS-PAGE analysis of the extracellular media at different times of culture. The selected colonies were used for large-scale production of recombinant AFP or proAFP in $200 \mathrm{ml}$ of buffered minimal methanol medium supplemented with histidine $(\mathrm{BMMH})$ medium. Incubation was carried out at $30^{\circ} \mathrm{C}$ for two days with strong aeration. Then, the extracellular medium was obtained by centrifugation and used to purify the recombinant proteins essentially as described before $[11,12]$. After dialysis of the extracellular medium against $50 \mathrm{mM}$ sodium phosphate, $\mathrm{pH} 7.0$, the proteins were retained on a cation exchange column of Amberlite IRC 50, equilibrated in the same buffer. After washing the column with $0.2 \mathrm{M} \mathrm{NaCl}$, the proteins were eluted with a $0.6 \mathrm{M}$ solution of the same salt. Then, the fractions containing the desired proteins were thoroughly dialyzed against water and lyophilized.

Fungal native natural AFP was also produced in A. giganteus MDH18894 liquid cultures and later purified following a standardized procedure described before [11].

Characterization of the purified proteins.

SDS- PAGE, Western immunoblots, protein hydrolysis and amino acid analyses were carried out as previously described [11,12,25-27]. The aminoterminal sequences were determined by Edman degradation using an Applied Biosystems model 477A sequencer. Mass spectrometry analysis was made as described before $[26,27]$ on an Autoflex III MALDI-TOF-TOF instrument (Bruker Daltonics, Bremen, Germany) with a smartbeam laser. Both types of determinations, protein sequencing and mass spectrometry, were performed at the C.I.B.-C.S.I.C. (Madrid, Spain) Proteomics and Genomics facility.

Absorbance measurements were performed on an Uvikon 930

spectrophotometer at $100 \mathrm{~nm} / \mathrm{min}$ scanning speed, at room temperature and in $1 \mathrm{~cm}$ optical path cells. Circular dichroism (CD) spectra were obtained on a Jasco 715 spectropolarimeter, equipped with a thermostated cell holder and a NesLab-111 circulating water bath, at $0.2 \mathrm{~nm} / \mathrm{s}$ scanning speed. The instrument was calibrated with (1)-10-camphorsulfonic acid. CD spectra were recorded in cylindrical cells of $0.1 \mathrm{~cm}$ optical path. Mean residue weight ellipticities were expressed in units of degree $\mathrm{x} \mathrm{cm}^{2} \mathrm{x} \mathrm{dmol}{ }^{-1}$. All these determinations were performed under conditions described elsewhere $[11,20,27]$.

In vitro antifungal activity of the purified proteins. 
The fungal rice pathogen $F$. verticilloides (supplied by the "Servei de Protecció Vegetals, Autonomous Government of Catalonia) was routinely cultured on potato dextrose agar (PDA) (Difco, Detroit, MI, USA) plates for 12 to 15 days at $28^{\circ} \mathrm{C}$. Spores were collected with distilled water, filtered and titrated with a hemacytometer.

The in vitro antifungal activity of both $P$. pastoris-produced recombinant AFPs, as well as the A. giganteus-produced natural AFP, was determined using a microtiter plate assay as previously described $[13,15,28]$. Briefly, $90 \mu \mathrm{l}$ of a fungal spore suspension at $10^{5}$ spores $/ \mathrm{ml}$ in PDB (potato dextrose broth; DIFCO, Detroit, MI, USA), containing $0.003 \%$ (wt/vol) chloramphenicol, was allowed to pre-germinate for $6 \mathrm{~h}$ at $28^{\circ} \mathrm{C}$. The purified AFP was added to the pre-germinated conidia to reach the desired final concentrations and the microtiter plates were incubated at $28^{\circ} \mathrm{C}$. The ability of the AFP proteins to inhibit fungal growth was determined by measuring optical density at $595 \mathrm{~nm}$ $\left(\mathrm{OD}_{595}\right)$ over time in a microplate reader (Synergy 2 Multi-Mode Microplate Reader, Biotek Instruments, Inc., VT, USA). In all the experiments made, three replicates were prepared for each treatment; the blank mean $\mathrm{OD}_{595}$ value from one row of mock inoculations was subtracted from the $\mathrm{OD}_{595}$ measurement of each well, and the mean and standard deviations (SD) were then calculated for each treatment.

The fungicidal activity of the $P$. pastoris produced AFP proteins was also assessed and compared with that of the natural active protein. For this, aliquots of fungal cultures at each peptide concentration treatment were taken at 1 day of incubation, diluted in distilled water, and spread onto peptide-free PDA plates to monitor viability.

\section{Results.}

\section{Protein purification and characterization.}

The homogeneity of the purified recombinant proteins produced by $P$. pastoris cells harboring either the pPICZaproAFP or the pPICZaAFP construct was initially assessed by SDS-PAGE. The protein fraction obtained from cells transformed with the plasmid pPICZaproAFP contained two immunoreactive polypeptides showing a lower mobility compared to that of the natural fungal protein (Fig. 2). This result suggested the presence of at least two molecular species of AFP-like proteins within this preparation. Mass-spectrometry analysis revealed that the two proteins had molecular masses of 6274 and 6474, whereas the expected mass for the mature fungal protein was 5798 (in the absence of free sulfihydril groups). This finding was consistent with the occurrence of partial cleavage at the two Ste13 sites and the formation of all the four possible disulfide bonds. Amino-terminal sequence confirmed the presence of two different $\mathrm{N}$-terminal sequences resulting from cleavage at the Kex2 and the first Ste13 site (Fig. 1). From this, it was concluded that the AFP protein produced in $P$. pastoris by using the pPICZaproAFP contained two protein species with an extension of 6 and 4 amino acid residues at the amino terminus of the wild-type natural fungal mature AFP (Fig. 1). This protein preparation was thereafter designated as proAFP.

On the other hand, the electrophoretic behavior of the protein purified from cells harboring pPICZaAFP was indistinguishable from that displayed by 
the natural fungal protein (Fig. 2). This protein also reacted with the antiserum against the natural protein and its molecular mass was coincident with that expected for the mature AFP (5798). Therefore, it was safely assumed that this protein corresponded to the fungal mature AFP, including the establishment of four disulfides, and was then designated as AFP*. The amino acid composition was coincident with that expected according to the characterization explained above. Finally, far-UV CD spectra of the two proteins studied, proAFP and AFP* $^{*}$, showed the unique shape of these particular polypeptides (Fig. 3). Their $C D$ spectra were very similar to those displayed by either the fungal mature AFP protein [11] or the inactive precursor of the A. giganteus-produced AFP protein [12], indicating the preservation of the global native conformation of the recombinant proteins.

The proAFP and AFP* proteins were purified from $P$. pastoris with yields of about 40.0 and $2.5 \mathrm{mg} / \mathrm{L}$ of BMMH producing medium, respectively.

\section{Antifungal activity of the P. pastoris-produced AFP proteins.}

The antifungal activity of the two AFPs produced in P. pastoris was measured against the fungal pathogen $F$. verticilloides and compared with the activity of the natural AFP produced by $A$. giganteus. AFP* and natural fungal AFP delay or complete inhibit fungal growth, being the natural protein only lightly more active than the recombinant one (i.e. $14 \%$ and $27 \%$ growth at a concentration of $0.5 \mu \mathrm{M}$ for the natural mature AFP and AFP*, respectively (Fig. $4 A)$.

The fungicidal activity of natural mature AFP and AFP* was assayed on pre-germinated conidia. Similar loss of viability of $F$. verticilloides spores was observed after $24 \mathrm{~h}$ of incubation with these two AFP proteins (Fig. 4B) (i.e. lost of viability spores by approximately $1 \log$ unit with at $2 \mu \mathrm{M}$ of $\mathrm{AFP}^{*}$, compare to lightly more lost of viability with natural mature AFP in identical conditions).

Finally, the proAFP protein had a low inhibitory activity of fungal growth and almost no effect on spore viability at $4 \mu \mathrm{M}$ (Fig. 4).

\section{Discussion.}

Developing biotechnological approaches for the production of antimicrobial peptides and proteins (AMPs) is of paramount importance to ensure efficient and safe applications of AMPs in biomedicine and agriculture. In addition to expanding our knowledge on the mode of action of AMPs their production might be useful for future use of AMPs as protective agents for plant protection, food, veterinary and human pharma sectors.

Within this idea, two versions of the AFP protein, proAFP and AFP*, have been produced in the heterologous system of $P$. pastoris with yields in the order of milligrams. Both recombinant proteins showed spectroscopic properties compatible with the assumption of the native fold of the original fungal protein. The most prominent feature of the far-UV CD spectrum of AFP is the presence of a strong positive band at $230 \mathrm{~nm}$ due to its high content of tyrosine residues [11]. This band is directly related to the native protein conformation but hampers calculations aimed to estimate secondary structure contents. The existence of different sets of disulfide bridges patterns within the same protein preparation further complicates this interpretation $[19,21]$. 
Purified AFP* displays an antifungal activity comparable to that of the Aspergillus produced AFP protein whereas the proAFP protein exhibits low antifungal activity under identical assay conditions. This observation suggests that the much lower yield of AFP* when compared to the other protein produced might be due to this lack of antifungal activity of proAFP. In this respect, it is worthwhile to remind that the natural AFP that is produced by A. giganteus is secreted to the extracellular medium as an inactive precursor (If-AFP), containing six extra residues at its amino-terminal end. This precursor form is further processed by still uncharacterized proteolytic activities of the final mature active form [12]. Taking into account that the six (or four) extra residues at the amino-terminal end of proAFP are completely different from those appearing in the $\mathrm{N}$-terminal of the natural inactive precursor (Table 1), it is tempting to speculate that any polypeptide extension at the AFP N-terminal would impair the establishment of essential interactions for its antifungal activity.

The production of active recombinant AFP will allow exploring in more detail the mode of action of this protein against target pathogens. Considering that $\mathrm{AFP}^{*}$ can be easily purified in large amounts from $P$. pastoris cultures, it offers an attractive model for its rapid and convenient production. As an example, direct application of AFP can be considered for protection of plants against infection by the fungal pathogen $F$. verticillioides. This fungus not only causes important losses in productivity in a large number of cereals and grasses but also reduces their quality by producing toxins, namely fumonisins, which affect human and animal health [29].

\section{Acknowledgements}

B.L.-G. is a Ramón y Cajal researcher from the Ministerio de Ciencia e Innnovación (MICINN) (Spain). This work was supported by Grants BFU200604404 and BIO2006-05583 from the Ministerio de Educación y Ciencia (MEC) (Spain) and within the center CONSOLIDER on Agrigenomics (MEC) and the Xarxa de referencia en Biotecnología (Generalitat de Catalunya). 


\section{References}

[1] M. Zasloff, Antimicrobial peptides of multicellular organisms, Nature 415 (2002) 389-395.

[2] R.E.W. Hancock, H.G. Sahl, Antimicrobial and host-defense peptides as new anti-infective therapeutic strategies, Nat. Biotechnol. 24 (2006) 1551-1557.

[3] E. Montesinos, Antimicrobial peptides and plant disease control, FEMS Microbiol. Lett. 270 (2007) 1-11.

[4] J.F. Marcos, A. Muñoz, E. Pérez-Payá, S. Misra, B. López-García, Identification and rational design of novel antimicrobial peptides for plant protection, Annu. Rev. Phytopathol. 46 (2008) 273-301.

[5] D. Peschen, H.P. Li, R. Fischer, F. Kreuzaler, Y.C. Liao, Fusion proteins comprising a Fusarium-specific antibody linked to antifungal peptides protect plants against a fungal pathogen, Nat. Biotechnol. 22 (2004) 732738.

[6] A.B. Moreno, G. Peñas, M. Rufat, J.M. Bravo, M. Estopá, J. Messeguer, B. San Segundo, Pathogen-induced production of the antifungal AFP protein from Aspergillus giganteus confers resistance to the blast fungus Magnaporthe grisea in transgenic rice, Mol. Plant Microb. Interact. 18 (2005) 960-972.

[7] K. Takase, K. Hagiwara, H. Onodera, Y. Nishizawa, M. Ugaki, T. Omura, S. Numata, K. Akutsu, H. Kumura, K. Shimazaki, Constitutive expression of human lactoferrin and its $\mathrm{N}$-lobe in rice plants to confer disease resistance, Biochem. Cell Biol. 83 (2005) 239-249.

[8] M. Coca, G. Peñas, J. Gómez, S. Campo, C. Bortolotti, J. Messeguer, B. San Segundo, Enhanced resistance to the rice blast fungus

Magnaporthe grisea conferred by expression of a cecropin A gene in transgenic rice, Planta 223 (2006) 392-406.

[9] F. Marx, U. Binder, E. Leiter, I. Pócsi, The Penicillium chrysogenum antifungal protein PAF, a promising tool for the development of new antifungal therapies and fungal cell biology studies, Cell Mol Life Sci. 65 (2008) 445-454.

[10] V. Meyer, A small protein that fights fungi: AFP as a new promising antifungal agent of biotechnological value, Appl. Microbiol. Biotechnol. 78 (2008) 17-28.

[11] J. Lacadena, A. Martínez-del-Pozo, M. Gasset, B. Patiño, R. CamposOlivas, C. Vázquez, A. Martínez-Ruiz, J.M. Mancheño, M. Oñaderra, J.G. Gavilanes, Characterization of the antifungal protein secreted by the mould Aspergillus giganteus, Arch. Biochem. Biophys. 324 (1995) 273281.

[12] A. Martínez-Ruiz, A. Martínez-del-Pozo, J. Lacadena, J.M. Mancheño, M. Oñaderra, J.G. Gavilanes, Characterization of a natural larger form of the antifungal protein (AFP) from Aspergillus giganteus, Biochim. Biophys. Acta 1340 (1997) 81-87.

[13] L. Vila, V. Lacadena, P. Fontanet, A. Martínez-del-Pozo, B. San Segundo A protein from the mold Aspergillus giganteus is a potent inhibitor of fungal plant pathogens, Mol. Plant Microb. Interact. 14 (2001) 13271331. 
[14] A.B. Moreno, A. Martínez-del-Pozo, M. Borja, B. San Segundo, Activity of the antifungal protein from Aspergillus giganteus against Botrytis cinerea, Phytopathology 93 (2003) 1344-1353.

[15] A.B. Moreno, A. Martínez-del-Pozo, B. San Segundo, Antifungal mechanism of the Aspergillus giganteus AFP protein against the rice blast fungus Magnaporthe grisea, Appl. Microbiol. Biotechnol. 72 (2006) 883-895.

[16] K.H. Oldach, D. Becker, H. Lörz, Heterologous expression of genes mediating enhanced fungal resistance in transgenic wheat, Mol Plant Microbe Interact. 14(2001) 832-838.

[17] M. Coca, C. Bortolotti, M. Rufat, G. Peñas, R. Eritja, D. Tharreau, A. Martínez-del-Pozo, J. Messeguer, B. San Segundo, Transgenic rice plants expressing the antifungal AFP protein from Aspergillus giganteus show enhanced resistance to the rice blast fungus Magnaporthe grisea, Plant Mol. Biol. 54 (2004) 245-259.

[18] M. Girgi, W.A. Breese, H. Lorz, K.H. Oldach, Rust and downy mildew resistance in pearl millet (Pennisetum glaucum) mediated by heterologous expression of the afp gene from Aspergillus giganteus, Transgenic Res. 15 (2006) 313-324.

[19] R. Campos-Olivas, M. Bruix, J. Santoro, J. Lacadena, A. Martínez-delPozo, J.G. Gavilanes, M. Rico, NMR solution structure of the antifungal protein from Aspergillus giganteus: evidence for cysteine pairing isomerism, Biochemistry 34 (1995) 3009-3021.

[20] A. Martínez-del-Pozo, V. Lacadena, J.M. Mancheño, N. Olmo, M. Oñaderra, J.G. Gavilanes, The antifungal protein AFP of Aspergillus giganteus is an oligonucleotide/oligosaccharide binding (OB) foldcontaining protein that produces condensation of DNA, J. Biol. Chem. 277 (2002) 46179-46183.

[21] G. Batta, T. Barna, Z. Gáspári, S. Sándor, K.E. Kövér, U. Binder, B. Sarg, L. Kaiserer, A.K. Chhillar, A. Eigentler, E. Leiter, N. Hegedüs, I. Pócsi, H. Lindner, F. Marx, Functional aspects of the solution structure and dynamics of PAF - a highly-stable antifungal protein from Penicillium chrysogenum, FEBS J. 276 (2009) 2875-2890.

[22] J.F. Marcos, M. Gandía, Antimicrobial peptides: to membranes and beyond, Expert Opin. Drug Discov. 4 (2009) 659-671.

[23] E. Leiter, H. Szappanos, C. Oberparleiter, L. Kaiserer, L. Csernoch, T. Pusztahelyi, T. Emri, I. Pócsi, W. Salvenmoser, F. Marx, Antifungal protein PAF severely affects the integrity of the plasma membrane of Aspergillus nidulans and induces an apoptosis-like phenotype, Antimicrob. Agents Chemother. 49 (2005) 2445-2453.

[24] S. Hagen, F. Marx, A.F. Ram, V. Meyer, The antifungal protein AFP from Aspergillus giganteus inhibits chitin synthesis in sensitive fungi, Appl. Environ. Microbiol. 73 (2007) 2128-2134.

[25] A. Martínez-Ruiz, A. Martínez-del-Pozo, J. Lacadena, J.M. Mancheño, M. Oñaderra, C. López-Otín, J.G. Gavilanes, Secretion of recombinant proand mature fungal $\alpha$-sarcin ribotoxin by the methylotrophic yeast Pichia pastoris: the Lys-Arg motif is required for maturation, Protein Expr. Purif. 12 (1998) 315-322.

[26] L. García-Ortega, V. de los Ríos, A. Martínez-Ruiz, M. Oñaderra, J. Lacadena, A. Martínez-del-Pozo, J.G. Gavilanes, Anomalous 
electrophoretic behavior of an acidic protein: ribonuclease $\mathrm{U} 2$, Electrophoresis 26 (2005) 3407-3413.

[27] E. Álvarez-García, L. García-Ortega, V. De los Ríos, J.G. Gavilanes, A. Martínez-del-Pozo, Influence of key residues on the heterologous extracellular production of fungal ribonuclease U2 in the yeast Pichia pastoris, Protein Expr. Purif. 65 (2009) 223-229.

[28] A. Muñoz, B. López-García, E. Pérez-Payá, J.F. Marcos, Antimicrobial properties of derivatives of the cationic tryptophan-rich hexapeptide PAF26, Biochem. Biophys. Res. Commun. 354 (2007) 172-177.

[29] P.E. Nelson, A.E. Desjardins, R.D. Plattner, Fumonisins, mycotoxins produced by Fusarium species: biology, chemistry, and significance, Annu. Rev. Phytopathol. 31 (1993) 233-252. 


\section{Table 1}

Amino-terminal sequences of the natural (If-AFP) [12] and recombinant (proAFP) inactive larger versions of AFP. The residue corresponding to the first position of mature AFP appears underlined.

\begin{tabular}{|l|l|}
\hline Protein & Sequence \\
\hline If-AFP & Asp-Glu-Ser-Ala-Val-Leu-Ala-Thr-... \\
\hline proAFP & Glu-Ala-Glu-Ala-Glu-Phe-Ala-Thr-... \\
\hline
\end{tabular}


Fig. 1. Detail of the sequences existing at the boundary of the a-factor signal peptide and the mature form of AFP for the two different plasmids employed. (A) pPICZaproAFP and (B) pPICZaAFP. The endonuclease restriction and signal peptide cleavage sites are also shown.

Fig. 2. Purity of the $P$. pastoris produced AFP proteins. SDS-PAGE (A) and Western blot (B) analysis of the natural and recombinant versions of AFP: fungal wild-type protein (lanes 1), proAFP (lanes 2), and AFP* (lanes 3). MW: Precision Plus Protein Standards (BioRad), molecular masses in KDa are indicated on the left side of the figure.

Fig. 3. Far-UV circular dichroism spectra of fungal native AFP (black circles) and its two recombinant versions: proAFP (white circles) and AFP* (gray circles).

Fig. 4. In vitro antifungal activity of natural AFP (black bars), AFP* (gray bars), and proAFP (striped bars) against $F$. verticilloides. (A) Fungal growth is expressed as mean values of percentage of the growth of control cultures (100\% represents fungal growth in PDB medium without AFP) \pm SD, at each peptide concentration and after $48 \mathrm{~h}$ of protein-fungi incubation. (B) Fungicidal activity is expressed as mean values of viable spores $/ \mathrm{ml} \pm \mathrm{SD}$, at each peptide concentration and after $24 \mathrm{~h}$ of protein-fungi incubation. Dot line represents the initial concentration of spores. 
A

5'..GGG GTA TCT CTC GAG AAAAGA GAG GCT GAA GCT GAA TTC GCC ACA TAC AAT GGC AAA...3'

.. Gly Val Ser Leu Gin Lys Arg, Glu Ala Glu Ala, Glu Phe Ala Thr Tyr Asn Ghy Lys..

Kex2 Ste13 Ste13

B

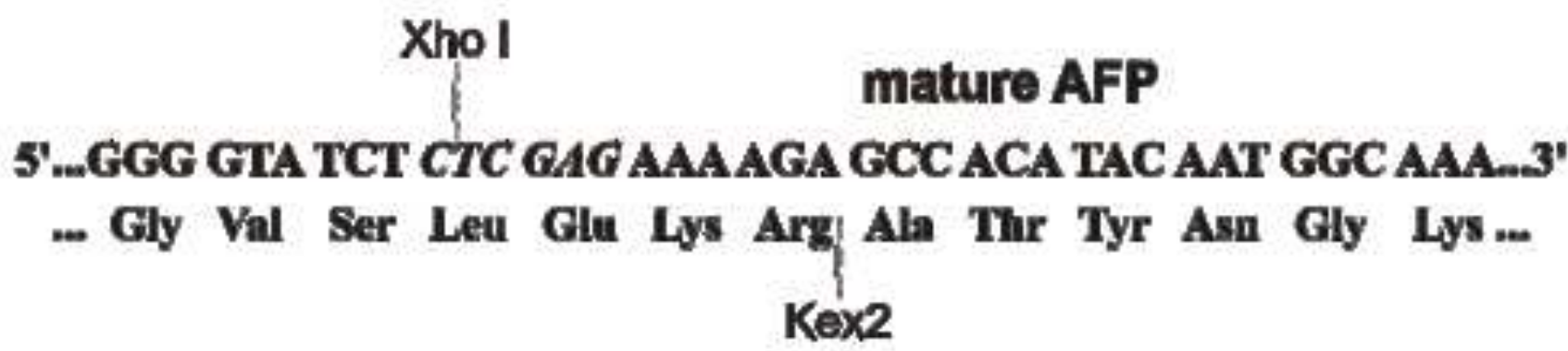

Figure 1 
Figure 2
Click here to download high resolution image

$\begin{array}{llllllll}\mathrm{KDa} & M W & 1 & 2 & 3 & 1 & 2 & 3\end{array}$

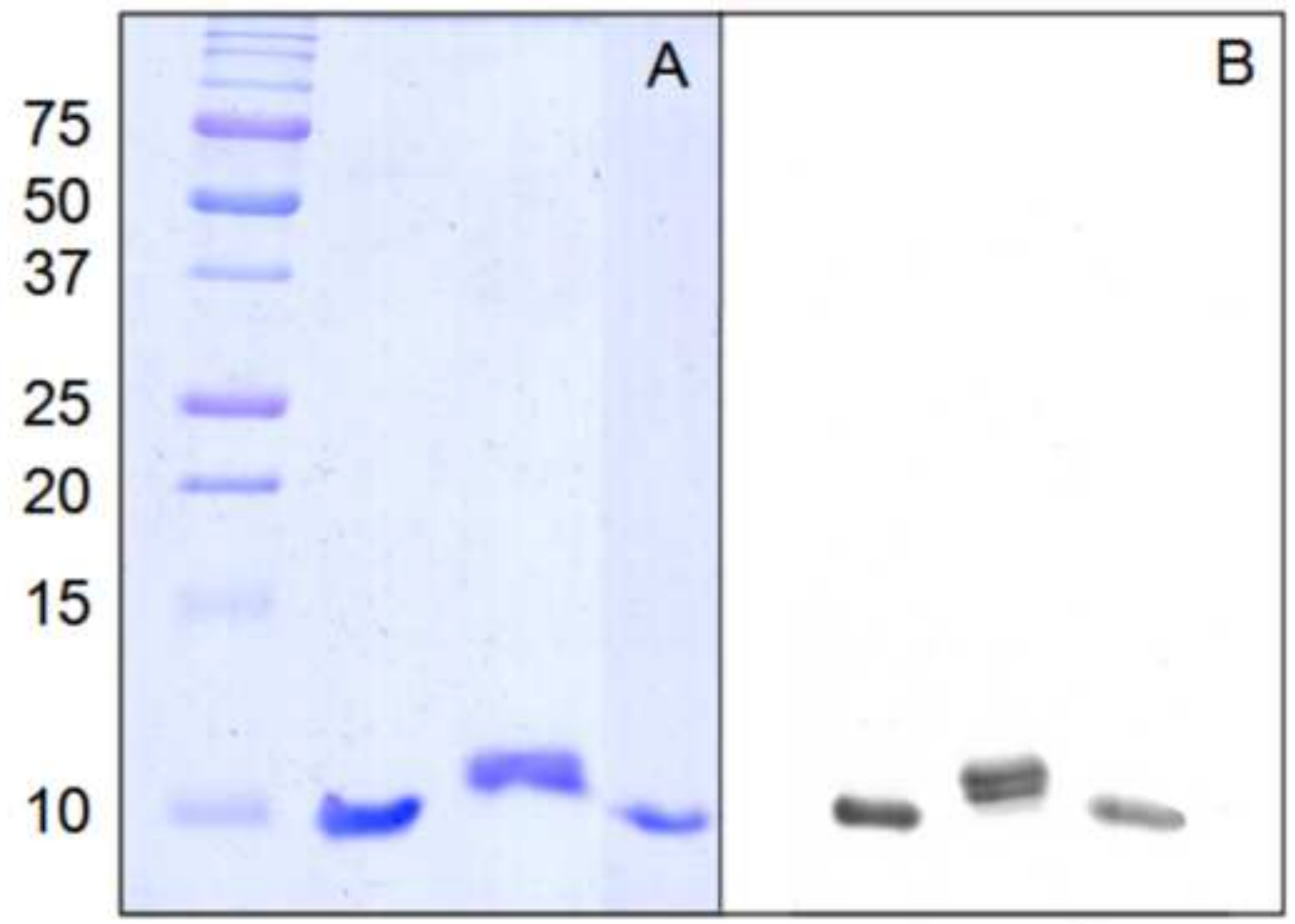




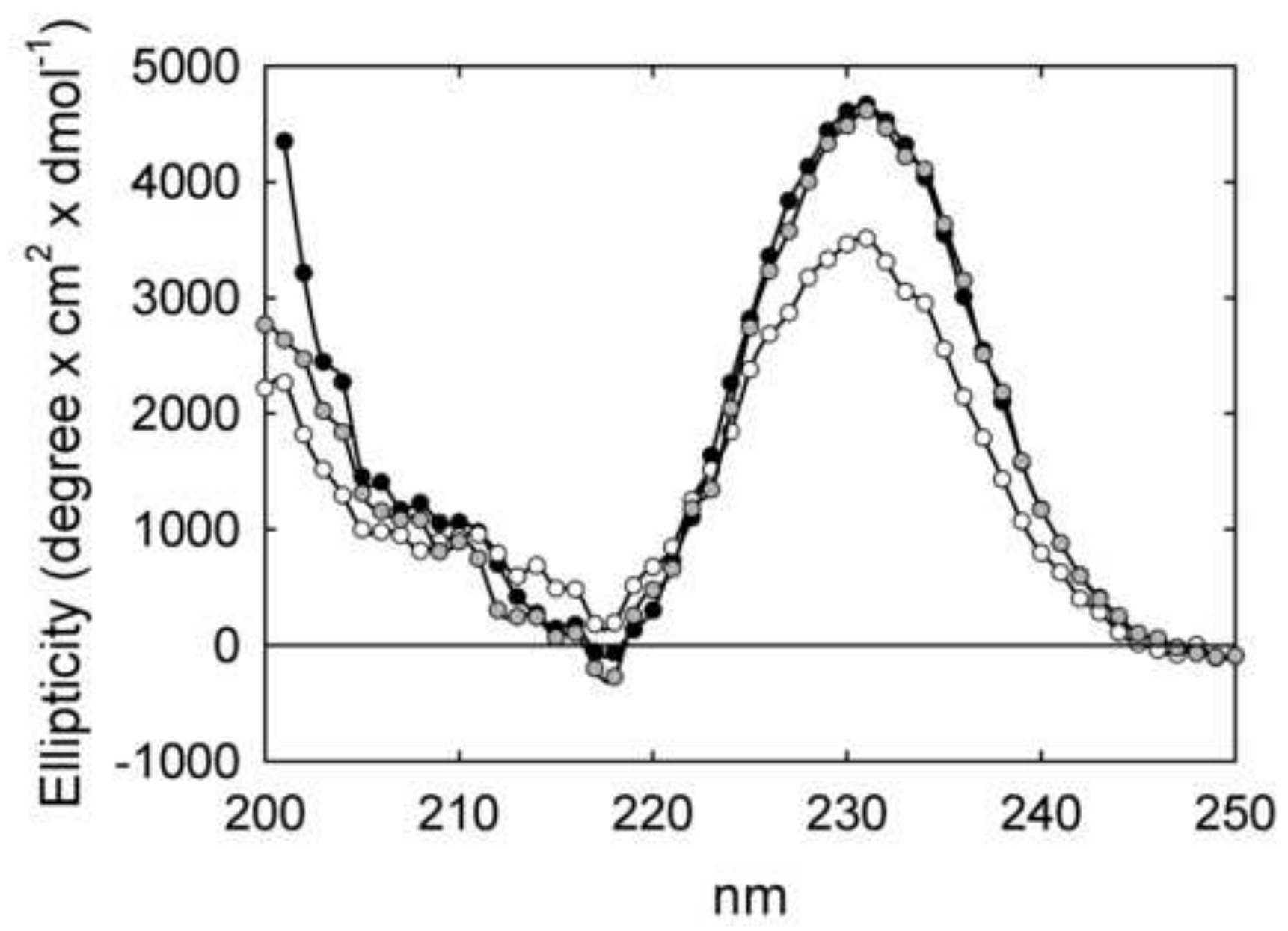

Figure 3 
Figure 4

Click here to download high resolution image
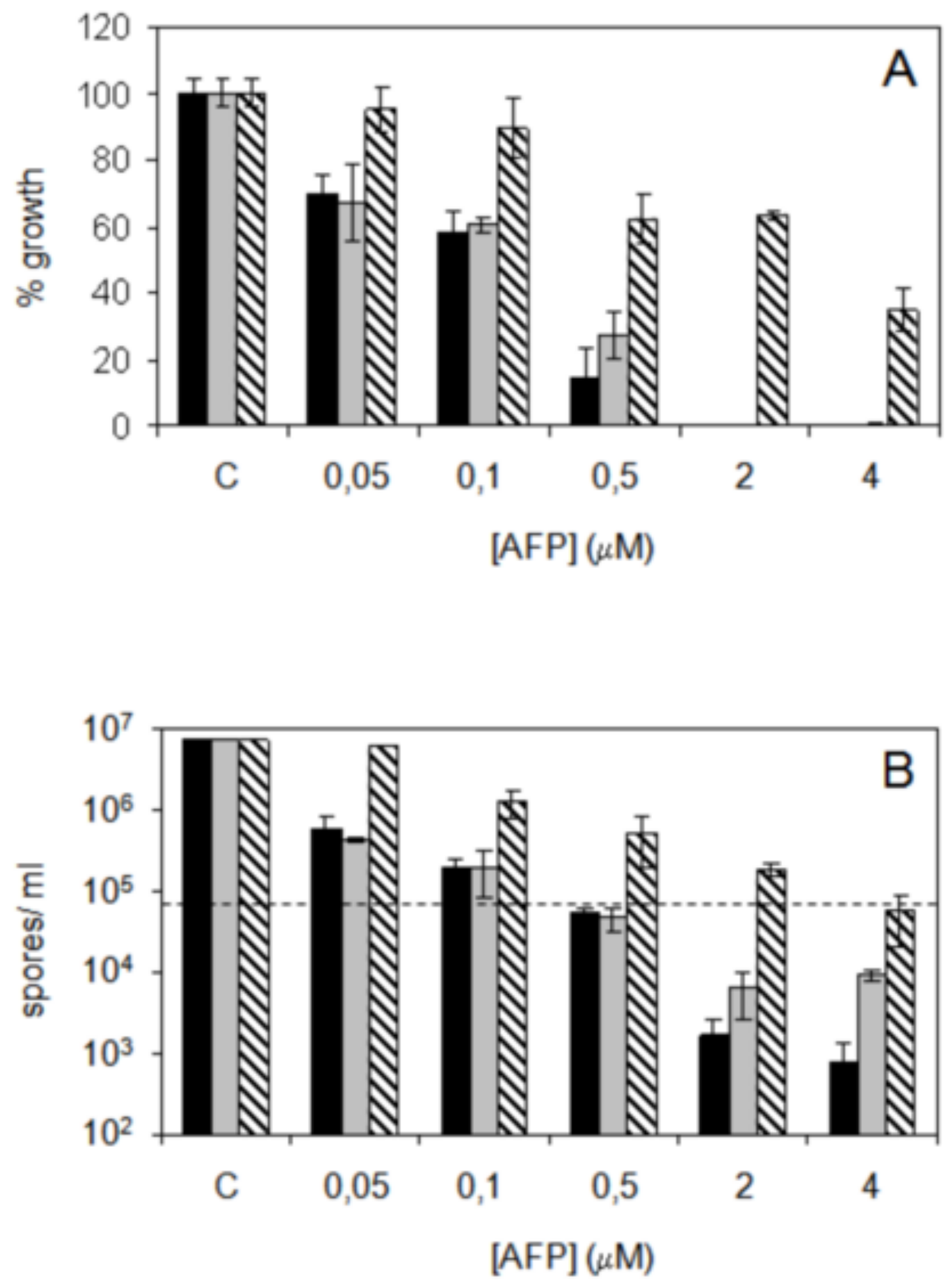

Figure 4 